\title{
The Use of Mobile Technology in Learning With Online and Offline Systems
}

\author{
Munoto Munoto, Electrical Engineering Department, Universitas Negeri Surabaya, Surabaya, Indonesia \\ Meini Sondang Sumbawati, Electrical Engineering Department, Universitas Negeri Surabaya, Surabaya, Indonesia \\ Satriana Fitri Mustika Sari, Civil Engineering Department, Universitas Negeri Surabaya, Surabaya, Indonesia
}

\begin{abstract}
Mobile phones can be functionalized in the process of learning using cellular devices and computing systems. The present study aims to (1) develop mobile learning applications and (2) find out student responses in the learning process using m-learning. This research used the 4D model (defining, designing, developing, and disseminating) written by Thiagarajan. Validation used a questionnaire to collect data, while effectiveness was revealed through student responses that took part in m-learning. The results showed 1) the application used in e-learning learning was very valid (\&gt; 85\%), and 2) research subjects (two classes) provided very positive feedback (\&gt; 85\%). It means that the mobile learning application developed is feasible to use because it has high validity and is able to increase students' positive responses. This study reveals that mobile learning applications can have a positive impact on student learning outcomes in the future.
\end{abstract}

\section{KEYWORDS}

Computing System, Mobile Learning Application, Mobile Technology

\section{INTRODUCTION}

Learning methods implemented by lecturers have been varied and have prioritized students to learn actively. Many lecturers teach by using power point, because the power point can present text, images, photos, animations are interesting. More effective and efficient, can reach many groups, and can be used repeatedly (Ko and Rossen, 2010, pp. 34-45). However, the learning with media power point also has weaknesses such as not all materials can be presented with power points, requiring special skills to pour messages or good ideas, using careful preparation, and need to be presented face to face. Seeing current lecturers have used learning with power point, indicating that this learning is not a problem. Learning with power point media and/or learning videos can be packaged in computers or laptops, which most teachers already have. This kind of learning media without being equipped with a controller or navigation tool that can be used by users, learning material can be realized in the form of CDs (Compact Disc), known as offline learning.

Online learning media is a media that is equipped with a controller/navigation tool that can be operated by the user, the user can manage and collect what the user needs. For online internet network learning is needed.Today almost all the world's population has known and used the internet. Many any medium, provided the author of the original work and original publication source are properly credited. 
lecturers did not use the internet for teaching and learning, and it affected students that ignored the internet as a learning media through mobile phone applications. Mobile learning applications helped students to study more often and more easily. Learning through the Internet gave more benefits towards growing a student's learning interest because the application materials contained educational content and entertainment (Ally, 2009, pp.34-56), which is also known as edutainment.

Learning development is in line with technological developments that use internet-based electronic devices. The Internet has several advantages such as easily obtainable information, its use as means of communication throughout the world in the forms of text, audio, or audio-visual without time and space limitations (Gilakjani, 2012). In addition, the materials provided met the student's needs. E-learning required computers or laptops for students to access the materials or lessons, although many students did not have access to these, but most of them had mobile phones that could be used to open a search engine (Dahlstorm et al., 2013). This kind of learning method was named mobile learning. M-learning (mobile learning) is a combination of e-learning and mobile computing, which is able to access any learning application anytime and from anywhere (Motiwala, 2007).With M-learning can change the attitude of people to use mobile phones to be very useful by learning anytime and anywhere (El-Husein and Kronje, 2010).

This study aimed to develop learning based on m-learning because (1) mobile phones are not widely used as a learning medium, and (2) the lack of learning content available through a mobile phone makes it not widely accessible. This study also provides mobile learning facilities to students that have not used mobile phones based on Android, such as the $\mathrm{X}$ phone and the web. The issues discussed are: (1) the feasibility of developing an e-learning portal with mobile orientation (that supports the Android, the X phone, and the web); (2) student responses during the application testing of an m-learning application for the Electric Circuit Materials courses and Evaluation in the Department of Electrical Engineering at the State University of Surabaya. As stated by Olofsson and Lendberg (2012), learning is constituted in the lived-in world, i.e., the world as it is experienced through social practice, and, as participation in a community with practice shapes and constitutes knowledge, that learners gradually master procedures for talking and acting through participation. Structurally, m-learning as part of e-learning. M-Learning is a combination of Electronic Learning (E-Learning) and Mobile Computing, which access a learning application at any time and from anywhere through mobile devices (Shih and Hung, 2007).

M-learning created a learning paradigm that can be used anywhere and for an indefinite amount of time. The M-learning function in learning was as a supplement (addition) that was optional, complementary, or substitutional. The results of the study on the MOBI-learn project found that $49 \%$ of students studied at home or at the work place, $21 \%$ of students studied outside the office, $5 \%$ of students studied outside the home, $2 \%$ of students studied at friend's house, $6 \%$ of students studied at a relaxing place, and $14 \%$ of students studied in the doctor's waiting room, cafe, mall, or even in a car (Sharples et al., 2007). M-Learning is a prospective learning medium that could be implemented in schools, colleges, and in universities considering the advanced development of Information and Communication Technologies due to the lower costs of mobile devices. M-learning refers to the use of handheld and mobile IT devices, such as PDAs, mobile phones, laptops, and PCs tablets, in learning. Wireless communication enables mobile learning, and, through the capability of multimedia technologies on wirelessly connected notebook computers, such as PDAs and even cellular phones, system developers have the possibility of implementing distance learning systems in mobile learning (Shih and Hung, 2007).

This study integrates the applications used on devices, which provides more advantages for wireless connections and the applications used on devices through the mobile network connection, which is connected to a web server. The m-learning-planning system consists of a management module and the mobile client. The system management module used was one of the existing digital learning systems, which, through the module manager, carried out m-learning management (Martin et al., 
2011; Rapuono and Zoino, 2006). The management module included adding m-learning courses and courseware, posting bulletins, as well as viewing the learning state.

The mobile client refers to the client software, which is accessed by the learners through the mobile terminal, and it connects the application server to complete the relevant learning operation through the mobile wireless network(s), such as WiFi wireless networking, and through the PC via data cable synchronization (Han et al., 2010). Planning the mobile client module consisted of: (1) the mobile side log-in module, (2) the resource data module, (3) the collaborative interaction module, and (4) the supporting services module.

\section{RESEARCH DESIGN}

This study was developed from a study referring to the 4D (Define, Design, Development, and Dissemination) model, which consisted of 4 steps, namely defining, designing, developing, and disseminating (Thiagarajan, 1974). Development refers to the learning development with m-learningoriented by using Android, X-phone and web mobile phones. The study involved students who programmed the courses during the odd semester of 2016/2017 at the Department of Electrical Engineering. These students became the respondents for the pilot study, which was a class project that developed m-learning.

\section{Defining Phase}

The defining phase consisted of front-end analysis, cognitive development analysis (learner analysis), task analysis, concept analysis, and specifying instructional objectives (Thiagarajan, 1974). The frontend analysis in the study found that not every student had a computer to access the material, while the university computer laboratory was always occupied. On the other hand, almost all students had a mobile phone, so it could be used not only for texting or short message service (SMS), but also for accessing the course materials. The learner analysis was the analysis of students who used the program to study course materials related to Electric Circuits 1 and 2 and the Learning Evaluation. The analysis was conducted through the documentation, and observations of student behaviors and activities were made when they used mobile phones supported with Android, X-phone (iphone X model) and the web. The task analysis identified the material characteristics related to the learning outcomes (LO) of the subjects using the m-learning applications. The Electric Circuits 1 and 2 and the learning Evaluation courses were selected according to basic competencies (BC) atau LO, which corresponded to the Semester Lesson Plan. The concept analysis was systematically arranged. These concepts were important and relevant, and they were prepared to meet all the work demands, as well as the development of science and technology while considering the Semester Lesson Plan. The concept analysis was very important for outlining the lesson plan that would be used for m-learning.

Specifying instructional objectives were carried out based on the task analysis and the concept analysis, which could be arranged in more detail in the course learning outcomes written in the Semester Lesson Plan. In addition, this phase described the activities carried out by the lecturers and the students in the teaching-learning process. This phase also specified the evaluation tools, materials, and the equipment needed for the teaching-learning activities. The learning purpose was the element used to measure the achievement of the learning objectives.

\section{Designing Phase}

The designing phase consisted of selecting an m-Learning media application to develop m-learning content and to design the m-learning web. Selecting the media was based on the concept that was important, and that was able to motivate students to learn. According to that concept, the appropriate medium was the mobile phone or hand phone HP (Android, the X-phone, and the web), which all support m-learning. Selecting important topics of particular subjects was outlined in flow chart form 
as a pre-production phase, which was continued by designing the display and the specified software to be used.

\section{Developing Phase}

The developing phase involved preparing the application for the Electric Circuits and the Learning Evaluation and the Vocational courses. Before the producing phase, and while in the developing phase, it was necessary to validate and to review all the m-learning devices and applications using media and electric or electronics experts to determine: (a) the validity of the concept; (b) the learning objectives; (c) the sound quality; (d) the quality of pictures and other illustrations; (e) the relevance of the question/task in regards to the learning objectives; and (f) the quality of the layout. Furthermore, a revision could be done based on the given input. During the developing phase, technical support and the m-learning infrastructure (network, audio, video, and text files) were designed.

\section{Data Collection}

Table 1 shows the data collection methods used in this study. Questionnaires were one of the methods used to collect data. Questionnaires were given to the students to unravel the usage period and their response to the Android applications. Questionnaires were filled out by the media and the course experts were used to determine the assessment criteria.The period of use of Android-based smartphones in the Department of Electrical Engineering (EE) and utilization, has six indicators of Performance quality, Software engineering, Curriculum, Presentation of materials, Evaluation, and Language. The assessment expert on Android has seven indicators consisting of Display quality, Software engineering, Presentation Material, Evaluation, Language, Maintainability, and Compatibility. As for the student response to android application has two indicators that is the result of the product, and effectiveness for students.

\section{Measurement Scale}

The instrument using the option: very good $=5$; $\operatorname{good}=4$; enough $=3$; less $\operatorname{good}=2$; and very unkind $=1$. Scoring is done by counting the percentage number that chooses an excellent and good option, beyond that it is not counted. Of those who choose very well and well in consultation with the standard criteria used. The average value used to decide is $(81-100) \%=$ very good; $(61-80) \%=$ good; $(41-60)=$ Medium; $(21-40) \%=$ bad; and below $21 \%=$ very bad. The product of this research is expected to be used by all students of electrical engineering department of one bachelor degree, this student who become populations. Because this research is a development research, the sample is a try out subject (Dörnyei, 2003). Subject is a bachelor's degree in electrical engineering program, which programmed several courses in the 2017-2018 semester of odd. As a trial activity using forty students.

Table 1. Method of collecting data

\begin{tabular}{|l|l|l|l|}
\hline \multicolumn{1}{|c|}{ Target } & \multicolumn{1}{|c|}{ Method } & \multicolumn{1}{c|}{ Instrument } & \multicolumn{1}{c|}{ Subject } \\
\hline $\begin{array}{l}\text { Period of use of Android-based } \\
\text { smartphone in the TE Department and } \\
\text { its utilization. }\end{array}$ & Questionnaire & Questionnaire sheet & Student \\
\hline Assessment experts on Android & Questionnaire & Check list, rubric checklist & $\begin{array}{l}\text { Lecturer experts, } \\
\text { media specialists } \\
\text { and subject } \\
\text { matter experts }\end{array}$ \\
\hline Student's responses to the android app & Questionnaire & Check list & Student \\
\hline
\end{tabular}




\section{Media Validation Instrument}

Table 2 shows the six aspects that were used to determine the validity of the medium. Each aspect was divided into several instruments in the questionnaires, which were used to measure the validity of the instructional media. These were the requirements when developing the instrument; all aspects were derived from the concept or from measured construction (Gable and Wolf, 2012; Walumbwa et al., 2008). These six aspects are translated into 24 indicators with the following distribution. Performance quality aspect has nine indicators, namely: the use of icon function / button, the presentation of the initial display or main menu that facilitates the determination of subsequent activities, clarity of the hierarchy menu and the material in the media, the suitability of the interface layout and page layout, the suitability of the use of text color, the font size used, the suitability of the proportion of the image presented with the media display, the suitability of the animation area presented with the media display, the loading process of the media (hank or crash), and the suitability of the view design with the user. The software engineering aspect consists of creativity in casting ideas, simplicity and simplicity in operation, and Ease of content searching (home, material, evaluation, information and information).

The curriculum aspect consists of the suitability of the learning objectives with core and basic competencies, as well as the main objectives and indicators of learning. The material presentation aspect consists of indicators: material conformity with indicators and learning objectives, conformity of concepts elaborated with concepts put forward by electronics experts, material organizational accuracy, and conformity with student cognitive development. The evaluation aspect consists of indicators of conformity with the learning objectives, and the suitability of the evaluation form with the concept presented. The last aspect of the language consists of the use of communicative language, the suitability of the language used with student development, the ease of understanding or the digestion of sentences used, and the grammar corresponding to the enhanced spelling. Each indicator is measured with one item, this instrument consists of 24 items of questioner.

The trial for m-learning was conducted in small classes. At this stage, the m-learning media was tried by forty students - registered for the Electric Circuits and the Learning Evaluation courses in the Department of Electrical Engineering, Faculty of Engineering, at the State University of Surabaya - to obtain empirical evidence to determine if it was valuable. The results of the limited trial were used to design the formula during the dissemination phase. Empirical testing was conducted by giving questionnaires to students to obtain their responses to determine their level of acceptance, the ease and attractiveness of the application, and the disadvantages of m-learning. The trials were adapted to the existing academic calendar used by the Department of Electrical Engineering at the State University of Surabaya. The effectiveness of and the student responses to learning media available through mobile learning was analyzed descriptively.

Table 2. Media validation instrument

\begin{tabular}{|l|l|l|}
\hline \multicolumn{1}{|c|}{ No. } & \multicolumn{1}{|c|}{ Aspect } & \multicolumn{1}{|c|}{ Item Total } \\
\hline 1 & Performance quality & 9 \\
\hline 2 & Software engineering & 3 \\
\hline 3 & Curriculum & 2 \\
\hline 4 & Presentation of material & 4 \\
\hline 5 & Evaluation & 2 \\
\hline 6 & Language & 4 \\
\hline Total & & 24 \\
\hline
\end{tabular}




\section{RESULTS AND DISCUSSION}

Android is defined as an operating system (mobile operating system) that has adopted the Linux operating system and is designed for touchscreen devices such as smartphones and PCs tablet, yet it has been modified (Vidas et al., 2011; Suprianto and Agustina, 2012). Seeing the situation, Google argued that the Android platform should be open and free. Therefore, almost every Android code launched has an open-source, Apache license that allows all Android users to download the full source code by themselves. The integrated approach of this application is one of the excellences of Android. Developers only need to concentrate on the application, as it can be applied in other devices.

The Android device configurations differ from one another, but they have commonly supported features, such as: (1) storage: SQLite is a light relational database for data storage; (2) connectivity: GSM/EDGE, IDEN, CDMA, EV-DO, UMTS, Bluetooth, WiFi, LTE and WiMAX; (3) messaging: SMS and MMS; (4) web browser: open-source WebKits include the Chrome V8 JavaScript engine; (5) hardware: accelerometer sensor, camera, digital compass, proximity sensor, and GPS; (6) a multitouch screen; (7) multitasking: supports several running applications simultaneously; (8) supports flash: Android 2.3 supports Flash 10.1; (9) supports other media formats: H.263, H.264, MPEG-4 SP, AMR, AMR-WB, AAC, HE-AAC, MP3, MIDI, OGG Vorbis, WAV, JPEG, PNG, GIF, and BMP.

Android was built based on object-oriented, where the elements structuring the operating system are reused objects. The perceived ease of use is the level that measures the people's reliance on effortlessly using a particular system. There were six indicators described, namely: (1) it's easy to learn; (2) it's controllable; (3) its clarity and understandability; (4) it's flexible; (5) it's easy to master; and (6) it's easy of use. The perceived ease of use positively influenced its acceptance by users/people. This concept is derived from the idea that a higher level of perceived ease in using a system resulted in a higher level of acceptance of the system by the users (Hsu, 2008).

The perceived usefulness stems from the reliance level of people on a system that is believed to improve their performance. There are six indicators that refer to perceived usefulness, namely: (1) the ability to work faster; (2) the ability to improve one's performance; (3) the ability to increase one's productivity; (4) the ability to add effectiveness; (5) the ability to simplify work; and (6) the ability to add benefits at work (Bar Ilan, 2008). The perceived usefulness effects acceptance due to the idea that a higher level of benefits gained yields a higher the level of acceptance. The m-learning display was made as simple and as easy as possible to simply the learning process for students using the application, and to escalate the level of acceptance for the system (López, 2009).

The display for offline m-learning (without internet connection) was preceded by the opening display. Figure 1 shows the first display that appears when the m-learning application is opened, which was developed at the State University of Surabaya (UNESA). It showed "Welcome to M-Learning UNESA" and a brief introduction followed. If people wanted to continue, they had to click the top right corner of their touchscreen.

Figure 2 shows the opening display for the courses in Electric Circuits. It showed "Welcome to Electric Circuits Android-based Learning." At the top (from right to left), the text stated "Menu" and "Home." The menu is selected to find teaching materials. Home is selected to return to the display for the Electric Circuits courses.

The menu selections displayed the learning materials for the Electric Circuits courses. Figure 3 displays the Menu, which shows seven chapters from the Electric Circuits materials that could be studied. To return to the previous display, "Home" is selected.

There were no significant differences among the display of other courses in offline m-Learning. As for the display for online m-Learning, it is started by displaying m-learning on the web. Figure 4 shows the menu display for m-learning on the Web, which would function if there were an adequate internet network. 
Figure 1. First display of $m$-learning applications

\section{M-Learning UNESA}

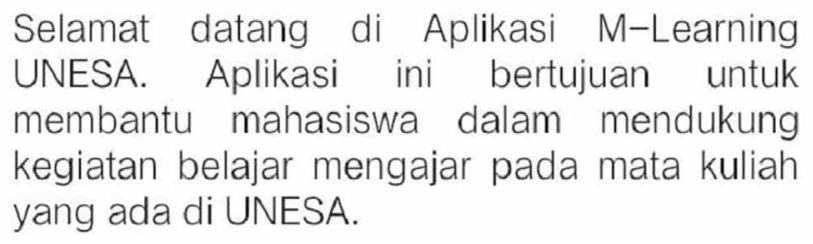

Figure 2. Display of electric circuit courses

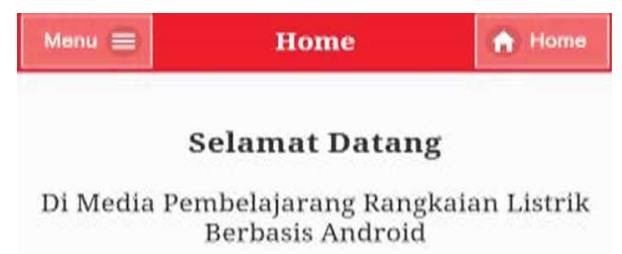

Copyright by TEKNIK INFORMATIKA U...

The online m-learning menu consists of the subjects studied in line with the program registered to the students. Figure 4 demonstrates the design of m-learning on the web by showing three subjects that could be studied. To select the subject, students need to click the box colored with the course color.

The result of the collected questionnaire was corrected by counting the percentage of respondents who chose good and excellent answers in every aspect, and tabulated in the following table. Table 3 shows the validation of IT experts, covering 6 aspects. Respondents who choose good and are very good answers in aspects: (1) the quality of the display gets a score of $80 \%$,indicating that the nine indicators are: the use of icon function / button, the presentation of the initial display or main menu that facilitates the determination of subsequent activities, clarity of the hierarchy menu and the material in the media, the suitability of the interface layout and page layout, the suitability of the use of text color, the font size used, the suitability of the proportion of the image presented with the media display, the 


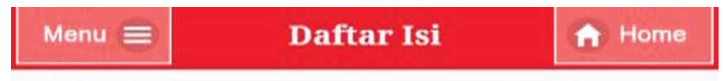

\author{
BAB I - PENGERTIAN DASAR DAN \\ PARAMETER RANGKAIAN
}

BAB I - PENGERTIAN DASAR DAN

PARAMETER RANGKAIAN

\author{
BAB II - RANGKAIAN LISTRIK \\ ARUS BOLAK-BALIK
}

BAB III - RESONANSI

BAB IV - DAYA LISTRIK (POWER)

BAB V - ANALISIS JARINGAN

ARUS MESH

\author{
BAB VI - ANALISIS JARINGAN \\ TEGANGAN TITIK SIMPUL (NODE \\ VOLTAGE NETWORK ANALYSIS)
}

\author{
BAB VII - ANALISIS JARINGAN
}

suitability of the animation area presented with the media display, the loading process of the media (hank or crash), and the suitability of the view design with the user, everything is good or valid; (2) software engineering scores $85 \%$, meaning that the three indicators arecreativity in casting ideas, simplicity and simplicity in operation, and Ease of content searching (home, material, evaluation, information and information), everything is very good or very valid; (3) the curriculum aspect gets a score of $80 \%$, indicating that the two indicators are the suitability of the learning objectives with core and basic competencies, as well as the main objectives and indicators of learning, everything is good orvalid; (4) the presentation of the material scores $85 \%$, giving the meaning that the two indicators are material conformity with indicators and learning objectives, conformity of concepts elaborated with concepts put forward by electronics experts, material organizational accuracy, and conformity with student cognitive development, everything is very good or very valid; (5) the evaluation aspect gets a score of $80 \%$, indicating that the two indicators consist of conformity with the learning objectives, and the suitability of the evaluation form with the concept presented,everything is good or valid;and (6) aspects of language score $85 \%$. This gives the meaning that the four indicators consist of the use of communicative language, the suitability of the language used with student development, the ease of understanding or the digestion of sentences used, and the grammar corresponding to the enhanced spelling, everything is very good or very valid.

Three aspects with are score of $80 \%$ indicates that the aspects are valid, and three other aspects with are score of $85 \%$ which means the validity is very good. The results shown in Table 3 illustrate that the validation score was $82.5 \%$, means overall m-learning has a very good validity. Thus, m-learning media showed function as a learning media.

Table 4 shows the score validity of the electrical field. Scores were evaluated using six aspects, namely the display quality is $80 \%$, the software engineering is $85 \%$, the curriculum is $85 \%$, the presentation of material is $90 \%$, their evaluation is $85 \%$, and the language $85 \%$. This M-learning has better validity, because nine aspects have excellent validity, and one other aspect has good validity. 
Figure 4. Display of menu of m-learning on the web

\section{Mata Kuliah}

Daftar mata kuliah yang memuat berbagai materi untuḱk kegiatan belajar mengajar.

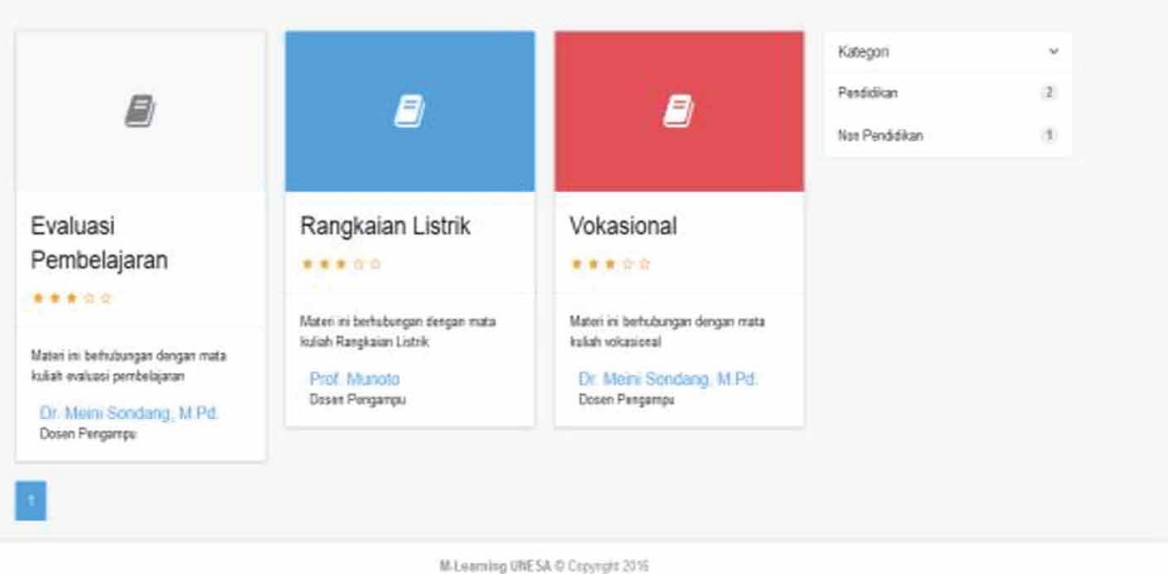

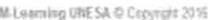

Table 3. Media validation instrument

\begin{tabular}{|l|l|l|l|}
\hline \multicolumn{1}{|c|}{ No. } & \multicolumn{1}{|c|}{ Aspect } & \multicolumn{1}{c|}{ Percentage (\%) } & \multicolumn{1}{c|}{ Remarks } \\
\hline 1. & Display quality & 80 & Good \\
\hline 2. & Software engineering & 85 & Very Good \\
\hline 3. & Curriculum & 80 & Good \\
\hline 4. & Presentation of material & 85 & Very Good \\
\hline 5. & Evaluation & 80 & Good \\
\hline 6. & Language & 85 & Very good \\
\hline
\end{tabular}

Table 4. The results of validation of electrical field

\begin{tabular}{|l|l|l|l|}
\hline \multicolumn{1}{|c|}{ No. } & \multicolumn{1}{|c|}{ Aspect } & \multicolumn{1}{c|}{ Percentage (\%) } & \multicolumn{1}{c|}{ Remarks } \\
\hline 1. & Display quality & 80 & Good \\
\hline 2. & Software engineering & 85 & Very Good \\
\hline 3. & Curriculum & 85 & Very Good \\
\hline 4. & Material presentation & 90 & Very Good \\
\hline 5. & Evaluation & 85 & Very Good \\
\hline 6. & Language & 85 & Very Good \\
\hline Average & & 85 & Very Good \\
\hline
\end{tabular}


The average score of the electrical field was $85 \%$, which was used to conclude that the m-learning media was excellent for use as a learning media.

When compared with the above data in this study for electric circuit subjects the average score of $82.5 \%$ increased to $85 \%$ for the electric field course, this shows that the application for the electric field course was higher than the same study for the electric circuit subject. But in quality both of them have the same validity that is very good or very valid, so that it is then tested to forty students. When compared with similar research for Financial Accounting courses with three aspects, namely (1) general aspects, (2) material substance aspects, and (3) learning design aspects, has an average validity score of $89.2 \%$ (Kurniawan and Khofifah, 2015). Although the average score is lower but still on the same standard, the validity is very high. On the other hand, our appraisal aspect is more detailed (six aspects compared to three aspects), so it can be believed that the application of M-Learning for Electrical Circuit and Electricity Courses is no less valid (Santos et al., 2014).

Table 5 shows the scores from the experts on m-learning applications. The validity was given based on seven aspects, namely the display quality is $85 \%$, the software engineering is $85 \%$, the material presentation is $90 \%$, their evaluation is $85 \%$, the language is $90 \%$, its maintainability is $85 \%$, and its compatibility is $85 \%$. Of the seven aspect validation of product experts turned out separately to seven aspects have a very good validity. According to the experts, this m-learning application received an average score of $86.4 \%$. Thus, this m-learning media showed the best function as a learning media.

Validation of the Semester Lesson Plan (SLP) was performed by two lecturers. Table 6 shows the results from these SLP assessment validators. The SLP assessment criteria consisted of: (1) designing learning objectives with a validation score is $85 \%$; (2) selecting and organizing teaching materials is $85 \%$; and (3) arranging the learning methods is $85 \%$. Thus the developed SLP is feasible to use because it separately and overall has a very good validity score. The Semester Lesson Plan validation results showed an average validation score of $85 \%$. These results showed that the SLP was very good or fit for use as a learning tool.

Table 5. The results of product experts

\begin{tabular}{|l|l|l|l|}
\hline \multicolumn{1}{|c|}{ No. } & \multicolumn{1}{|c|}{ Aspect } & \multicolumn{1}{c|}{ Percentage (\%) } & \multicolumn{1}{c|}{ Remarks } \\
\hline 1. & Display quality & 85 & Very good \\
\hline 2. & Software engineering & 85 & Very good \\
\hline 3. & Presentation Materials & 90 & Very good \\
\hline 4. & Evaluation & 85 & Very good \\
\hline 5. & Language & 90 & Very good \\
\hline 6. & Maintainable & 85 & Very good \\
\hline 7 & Compatibility & 85 & Very good \\
\hline Average & & $86.4 \%$ & Very good \\
\hline
\end{tabular}

Table 6. Results of the assessment of the validator on SLP

\begin{tabular}{|l|l|l|l|}
\hline \multicolumn{1}{|c|}{ No. } & \multicolumn{1}{|c|}{ Aspect } & \multicolumn{1}{c|}{ Percentage (\%) } & \multicolumn{1}{c|}{ Remarks } \\
\hline 1. & Formulation of Learning Objectives & 85 & Very Good \\
\hline 2. & $\begin{array}{l}\text { The selection and organization of teaching } \\
\text { materials }\end{array}$ & 85 & Very Good \\
\hline 3. & Learning methods & 85 & Very Good \\
\hline Percentage Total & $85 \%$ & Very Good \\
\hline
\end{tabular}


Table 7 shows the summary of student responses to m-learning. Student responses to m-Learning consisted of the responses given by students that used the m-learning media in the course for Electric Circuits 1 and 2, as well as in evaluating the Learning and Vocational learning media. The aspects measured to determine student responses consist of the results of product, and effectiveness for students. Aspects of the results of product have score $85 \%$, and effectiveness for students is $85 \%$. Overall response students have score $85 \%$. This means that the response of students to the learning of $\mathrm{m}$-learning is very positive, and this media tends to improve the learning outcomes. A high student response score (85\%) indicates that students are very happy to learn with m-learning media. This causes the students' learning motivation is very high, and then can improve learning outcomes to be higher. In other words, learning with m-learning media can be more effective.

The finding of excellent learning m-learning validity (85\%) gives assurance that the developed m-learning can meet the validity requirements. It deals with similar programs for computer system courses with very good validity scores (88.14) (Dawe and Nguyen, 2007). The learning of m-learning in electric field mathematics also has the same validity score, excellent with score $(85 \%)$. The validity of the product expert is also very high, and slightly higher at $86.4 \%$. From the above findings it can be mentioned that the validity of learning m-learning can be used.

The validation of the Semester Lesson Plan (SLP) has a validation score of $85 \%$ with criteria very good. This indicates that the formulation of learning materials is very precise and measurable, materials and learning organizations, and learning methods are very precise. The accuracy of SLPs that are carried out according to the steps can improve learning outcomes. This is in accordance with Dunlosky's invention, ie learning that is done with the objectives, methods, and selection is very appropriate will be more effective in improving learning outcomes (Dunlosky et al., 2014).

According to experts, m-learning applications get an average score of $86.4 \%$ with very good assessment criteria. This means, the m-learning media under study has a display of display, software, material presentation, evaluation, language, maintainable, and compatibility is very good. Such circumstances can improve student learning outcomes. This is in accordance with the research (Sarrab et al., 2016), that m-learning applications display, software, material presentation, evaluation, language, maintainable, and compatibilitygood, learning outcomes of learners to be better (Sarrab et al., 2016).

Overall student response has an average score of $85 \%$ with very good or very positive assessment criteria. A very positive attitude toward m-learning can bring students learning fun by using m-learning media. If students enjoy learning to use m-learning, student learning motivation will increase. In conclusion, learning m-learning media can increase motivation to the students who use it. This is in accordance with the results of research by Mohammadi (2015), which concludes that there is a significant positive correlation (0.82) between the use of m-learning to student learning motivation. If the students' learning motivation increases tend to make student learning outcomes increase, because there is a significant positive relationship (0.79) between student learning motivation and learning outcomes (Paechter, 2010). Temporary conclusion, students' learning responses increase, learning motivation increases, then will bring learning results increase. In other words, learning with m-learning media can be more effectively

The validity of learning with m-learning media developed in this study, according to students is very good, according to the expert product is very good. Students' responses in learning by using

Table 7. The recapitulation of student response

\begin{tabular}{|l|l|l|l|}
\hline \multicolumn{1}{|c|}{ No. } & \multicolumn{1}{c|}{ Aspect } & \multicolumn{1}{c|}{ Percentage (\%) } & \multicolumn{1}{c|}{ Remarks } \\
\hline 1 & The results of product & 85 & Very Good \\
\hline 2 & Effectiveness for students & 85 & Very Good \\
\hline Total & & 85 & Very Good \\
\hline
\end{tabular}


m-learning media are very good, learning motivation increases, and learning outcomes tend to increase. Lesson Plan Semester (LSP) validity is very good, which can cause more tendency to improve learning outcomes. It can be said that learning with m-learning media developed is very valid and effective.

The reality shows that almost all people use mobile technology.Students use cellular technology to learn, even though there are no assignments from lecturers. This fact is a consequence of their social life outside the classroom, but it is not considered a practice of learning related to the use of devices (Margaryan, 2011). On the other hand, faculty and students both believe that utilizing mobile devices for academic activities is very effective (Gikas and Grant, 2013). On the other hand it was found that almost all students owned handphones, but in a relaxed or independent state they used handphones with less useful activities (Mulkan et al., 2013). Based on these findings it can be concluded that using M-learning can change students' attitudes to learning by using M-learning. With M-Learning students can study anytime and anywhere, using their mobile phones.

In addition to all these findings, interviews revealed that trainers and lecturers had accessed videos through the monthly Nokia Education Delivery software, which they used for mentoring (Harley et al., 2006). Trainers and lecturers are used to communicate with each other and to the head. Most lecturers admit that the material found is useful and has value for training and mentoring. They learn, not only from mentors but also from peers, how to become reflective lecturers. Most lecturers agree that the M-Learning program has an impact on both professional development and student achievement (Kapp, 2012). On that basis, the teacher or lecturer is highly recommended to make the M-Learning application on all the subjects he has built into a CD. Furthermore, educational institutions are encouraged to make M-Learning online. Then online learning needs to be done professionally, so that it can do distance learning. Learning by using m-learning media can be done anywhere \& anytime, can learn repeatedly, make learning easier, add insight, can always discussion with colleagues, and enjoy learning (Simonson et al., 2014). On the basis of the above analysis can be concluded that m-learning media developed feasible to be used as learning.

\section{CONCLUSION}

Developing learning using mobile learning applications is valid and can be applied in colleges and universities. Student responses to study in Electrical Circuit and electrical Field courses using mobile learning applications were evaluated at $85 \%$, which was considered very good. Good learning responses can increase learning motivation. Finally, the teaching and learning process using mobile learning improves student learning outcomes. On that basis mobile learning needs to be encouraged in college. 


\section{REFERENCES}

Ally, M. (2009). Mobile learning: Transforming the delivery of education and training. AU Press.

Andrews, R., \& Haythornethwaite, C. (Eds.). (2007). A theory of learning for the mobile age. The Sage Handbook of Elearning Research.

Bar-Ilan, J. (2008). Which h-index?-A comparison of WoS, Scopus and Google Scholar. Scientometrics, 74(2), 257-271. doi:10.1007/s11192-008-0216-y

Dahlstrom, E., Walker, J. D., \& Dziuban, C. (2013). ECAR study of undergraduate students and information technology. Research Report EDUCAUSE Center for Analysis and Research. ECAR.

Dawe, S., \& Nguyen, N. (2007). Education and training that meets the needs of small business: A systematic review of research. National Centre for Vocational Education Research Ltd.

Dörnyei, Z. (2003). Questionnaires in second language research: Construction, administration, and processing. Lawrence Erlbaum Associates Inc.

Dunlosky, J., Rawson, K. A., Marsh, E. J., Nathan, M. J., \& Willingham, D. T. (2013). Improving students' learning with effective learning techniques: Promising directions from cognitive and educational psychology. Psychology of Science and Publicaion International, 14(1), 4-58. doi:10.1177/1529100612453266 PMID:26173288

El-Hussein, M. O. M., \& Cronje, J. C. (2010). Defining mobile learning in the higher education landscape. Journal of Educational Technology \& Society, 13, 12-21.

Gable, R. K., \& Wolf, M. B. (2012). Instrument development in the affective domain: Measuring attitudes and values in corporate and school settings. Springer-Verlag.

Gikas, J., \& Grant, M. M. (2013). Mobile computing devices in higher education: Student perspectives on learning with cellphones, smartphones \& social media. Industry and Higher Education, 19, 18-26.

Gilakjani, A. P. (2012). The significant role of multimedia in motivating EFL learners' interest in English language learning.I. J. Modern Education and Computer Science, 4, 57-60.

Han, J., Yin, H., Liu, J., \& Dong, J. (2010). Design and research of Android Mobile Learning system with the support GAE. Proceedings of 2 nd International Conference of Information and Multimedia Technology (ICIMT 2010), 130-135.

Harley,D., Henke, J., Lawrence, S., Miller, I., Perciali, I., \& Nasatir, D. (n.d.). Use and users of digital resources: A focus on undergraduate education in the humanities and social sciences. UC Berkeley: Center for Studies in Higher Education.

Hsu, I.C. (2008). Knowledge sharing practices as a facilitating factor for improving organizational performance through human capital: A preliminary test. Expert System and Application, 35, 1316-1326.

Kapp, K. M. (2012). The gamification of learning and instruction: game-based methods and strategies for training and education. John Wiley \& Sons.

Ko, S., \& Rossen, S. (2010). Teaching online: A practical guide. Routledge.

Kurniawan, I., \& Khofifah, S. (2015). Pengembangan aplikasi mobile learning berbasis kebudayaan nasional (Bimayana) untuk pembelajaran matakuliah akuntasi keuangan. Komputerisasi Akuntansi STEKOM.

López, J. G., Royo, T. M., Laborda, J. G., \& Calvo, F. G. (2009). Methods of adapting digital content for the learning process via mobile devices. Procedia: Social and Behavioral Sciences, 1(1), 2673-2677. doi:10.1016/j. sbspro.2009.01.472

Margaryan, A., Littlejohn, A., \& Voj, G. (2011). Are digital natives a myth or reality? University students' use of digital technologies. Computer Education, 56(2), 429-440. doi:10.1016/j.compedu.2010.09.004

Martin, S., Diaz, G., Plaza, I., Ruiz, E., Castro, M., \& Peire, J. (2011). State of the art of frameworks and middleware for facilitating mobile and ubiquitous learning development. Journal of Systems and Software, 84(11), 1883-1891. doi:10.1016/j.jss.2011.06.042 
Mohammadi, H. (2015). Investigating users' perspectives on e-learning: An integration of TAM and IS success model. Computers in Human Behavior, 45, 359-374. doi:10.1016/j.chb.2014.07.044

Motiwalla, L. F. (2007). Mobile learning: A framework and evaluation. Computer Education, 49(3), 581-596. doi:10.1016/j.compedu.2005.10.011

Mulkan, D. S., Sjafirah, N. A., Gumilar, G., \& Sos, S. (2013). The Study Of Mass Media Use By Islamic Boarding School Students In West Java Province. The International Journal of Social Sciences (Islamabad), 18, 1-11.

Olofsson, A. D., \& Lendberg, J. O. (2012). Informed design of educational technologies in higher education: Enhanced learning and teaching. IGI Global. doi:10.4018/978-1-61350-080-4

Paechter, M., Maier, B., \& Macher, D. (2010). Students' expectations of, and experiences in e-learning: Their relation to learning achievements and course satisfaction. Computer Education, 54(1), 222-229. doi:10.1016/j. compedu.2009.08.005

Rapuano, S., \& Zoino, F. (2006). A learning management system including laboratory experiments on measurement instrumentation. IEEE Transactions on Instrumentation and Measurement, 55(5), 1757-1766. doi:10.1109/TIM.2006.880309

Santos, M.E.C., Chen, A., Taketomi, T., Yamamoto, G., Miyazaki, J., \& Kato, H. (2014). Augmented reality learning experiences: Survey of prototype design and evaluation. IEEE T Learning of Technology, 7, 38-56.

Sarrab, M., Elbasir, M., \& Alnaeli, S. (2016). Towards a quality model of technical aspects for mobile learning services: An empirical investigation. Computer and Human Behavior, 55, 100-112.

Shih, T. K., \& Hung, J. C. (2007). Future directions in distance learning and communication technologies. Idea Group Publishing. doi:10.4018/978-1-59904-376-0

Simonson, M., Smaldino, S., \& Zvacek, S. M. (2014). Teaching and learning at a distance: Foundations of distance education. IAP.

Suprianto, D., \& Agustina, R. (2012). Pemrograman aplikasi android, step by step membuat aplikasi android untuk smartphone dan tablet. Media Kom.

Thiagarajan, S., Semmel, D. S., \& Semmel, M. I. (1974). Instructional development for training teachers of exeptional children: A sourcebook. Indiana University Press.

Vidas, T., Zhang, C., \& Christin, N. (2011). Toward a general collection methodology for android devices. Digital Investigation, 8, S14-S24. doi:10.1016/j.diin.2011.05.003

Walumbwa, F. O., Avolio, B. J., Gardner, W. L., Wernsing, T. S., \& Peterson, S. J. (2008). Authentic leadership: Development and validation of a theory-based measure. Journal of Management, 34(1), 89-126. doi:10.1177/0149206307308913 